\title{
Engineering mosquito population for vector control
}

\author{
Nikolai Windbichler ${ }^{1 *}$, Roberto Galizzi ${ }^{1}$, Austin Burt ${ }^{2}$, Andrea Crisanti ${ }^{1}$ \\ From Challenges in malaria research \\ Basel, Switzerland. 10-12 October 2012
}

\section{Background and Results}

The development of genetically engineered malaria-resistant mosquitoes has shown, as a proof-of-principle, the possibility of targeting the mosquito's ability to serve as a disease vector $[1,2]$. The translation of these achievements into control measures relies on the availability of an effective gene drive technology to spread a genetic modification from laboratory mosquitoes to field populations. We have suggested that homing endonuclease genes (HEGs), a class of simple selfish genetic elements, could be exploited to develop vector control strategies aimed at spreading in a target population either novel genes that impair the mosquitoes ability to function as vector for malaria or genetic modifications that disrupt their reproductive capability [3-5]. To assess the ability of HEG based constructs to spread a genetic modification into target mosquito populations we have generated transgenic mosquitoes carrying a synthetic genetic element containing the l-Scel homing endonuclease selectively activated in male during spermatogenesis. We show that the 1-Scel element is able to rapidly invade receptive $A$. gambiae cage populations, validating mathematical models for the transmission dynamics of HEGs. Molecular analysis confirms that the expression of 1-Scel in the male germline induces high rates of both cleavage of receptive chromosomes and gene conversion, which results in the gain of the l-Scel gene, and underlies the observed genetic drive. Furthermore we also show that different HEGs can be engineered to reprogram their sequence specificity to selectively target A. gambiae sequence. These findings provide a new perspective for the implementation of genetic control measures by demonstrating a mechanism by which linked genes could be spread through vector populations. Genes that interfere with A. gambiae ability to transmit

${ }^{1}$ Imperial College London Department of Life Sciences, South Kensington Campus, London, SW7 2AZ, UK

Full list of author information is available at the end of the article
Plasmodium falciparum malaria without unbalancing key mosquito physiological processes are yet to be found, however candidates genes that impair mosquito reproductive capability are potentially available. In previous reports we showed that the homing endonuclease 1-Ppol recognizing a unique site within the Anopheles gambiae 28S ribosomal genes could be used to selectively target $\mathrm{X}$ chromosome carrying spermatozoa. Our data demonstrated that in heterozygous males, the expression of 1-Ppol in the testes induced a strong bias toward Y chromosome-carrying spermatozoa. However these male mosquitoes also induced complete early dominant embryo lethality in crosses with wild-type females. Irrespectively of the inheritance of the 1-Ppol the spermatozoa carried a substantial amount of 1-Ppol protein that attacked the maternally inherited chromosome $\mathrm{X}$ of the embryo. Here we show that transgenic male mosquitoes expressing a destabilized form of 1-Ppol during the process of spermatogenesis generated vital male only progeny thereby decoupling the sex distortion and the embryo lethality phenotype resulting from targeting the $\mathrm{X}$ chromosome. Our results show how, using sequence-specific genetic drive elements like HEGs, the step from the genetic engineering of individuals to the genetic engineering of populations can be taken.

\section{Acknowledgement}

We thank the members of the Northwest Genome Engineering Consortium laboratories of David Baker, Ray Monnat, Andy Scharenberg and Barry Stoddard for their collective support of HEG engineering. Alden F.M. Hackmann provided graphics support. Funded by a grant from the Foundation for the National Institutes of Health through the Vector-Based Control of Transmission: Discovery Research (VCTR) program of the Grand Challenges in Global Health initiative and by NIH RL1 awards GM084433 to D.B. and CA133831 to R.J.M., Jr.

\section{Author details}

${ }^{1}$ Imperial College London Department of Life Sciences, South Kensington Campus, London, SW7 2AZ, UK. ${ }^{2}$ Imperial College London Centre for Population Biology, Silwood Park, Ascot, SL5 7PY, UK.

\section{() Biomed Central}




\section{References}

1. Curtis CF: Possible use of translocations to fix desirable genes in insect pest populations. Nature 1968, 218:368-369.

2. Moreira $L A$, et al: Bee venom phospholipase inhibits malaria parasite development in transgenic mosquitoes. J Biol Chem 2002,

277:40839-40843, doi:10.1074/jbc.M206647200M206647200 [pii].

3. Burt A: Site-specific selfish genes as tools for the control and genetic engineering of natural populations. Proc Biol Sci 2003, 270:921-928.

4. Windbichler $\mathrm{N}$, et al: Homing endonuclease mediated gene targeting in Anopheles gambiae cells and embryos. Nucleic Acids Res 35:5922-5933.

5. Windbichler N, Papathanos PA, Crisanti A: Targeting the $X$ chromosome during spermatogenesis induces $Y$ chromosome transmission ratio distortion and early dominant embryo lethality in Anopheles gambiae. PLoS Genet 2008, 4:e1000291.

doi:10.1186/1475-2875-11-S1-044

Cite this article as: Windbichler et al:: Engineering mosquito population for vector control. Malaria Journal 2012 11(Suppl 1):044.

\section{Submit your next manuscript to BioMed Central} and take full advantage of:

- Convenient online submission

- Thorough peer review

- No space constraints or color figure charges

- Immediate publication on acceptance

- Inclusion in PubMed, CAS, Scopus and Google Scholar

- Research which is freely available for redistribution

Submit your manuscript at www.biomedcentral.com/submit 